\title{
Roles of adjuvant and route of vaccination in antibody response and protection engendered by a synthetic matrix protein 2-based influenza $A$ virus vaccine in the mouse
}

\author{
Krystyna Mozdzanowska1, Darya Zharikova1,2, Mare Cudic ${ }^{1,3}$, Laszlo Otvos ${ }^{1,4}$ \\ and Walter Gerhard*1
}

Address: ${ }^{1}$ Immunology Program, The Wistar Institute, Philadelphia, USA, ${ }^{2}$ Department of Pathology and Laboratory Medicine, University of Wisconsin Hospital and Clinics, Madison, USA, ${ }^{3}$ Department of Chemistry and Biochemistry, Florida Atlantic University, Boca Raton, USA and ${ }^{4}$ Temple University, Sbarro Institute, Philadelphia, USA

Email: Krystyna Mozdzanowska - kmoz@wistar.org; Darya Zharikova - DZharikova@uwhealth.org; Mare Cudic - mcudic@fau.edu; Laszlo Otvos - otvos@temple.edu; Walter Gerhard* - gerhard@wistar.org

* Corresponding author

Published: 31 October 2007

Virology Journal 2007, 4:118 doi:10.1186/1743-422X-4-118

This article is available from: http://www.virologyj.com/content/4/I/II8

(c) 2007 Mozdzanowska et al; licensee BioMed Central Ltd.

This is an Open Access article distributed under the terms of the Creative Commons Attribution License (http://creativecommons.org/licenses/by/2.0), which permits unrestricted use, distribution, and reproduction in any medium, provided the original work is properly cited.
Received: 6 September 2007

Accepted: 3I October 2007

\begin{abstract}
Background: The M2 ectodomain (M2e) of influenza A virus (IAV) strains that have circulated in humans during the past 90 years shows remarkably little structural diversity. Since M2e-specific antibodies (Abs) are capable of restricting IAV replication in vivo but are present only at minimal concentration in human sera, efforts are being made to develop a M2e-specific vaccine. We are exploring a synthetic multiple antigenic peptide (MAP) vaccine and here report on the role of adjuvants (cholera toxin and immunostimulatory oligodeoxynucleotide) and route of immunization on $\mathrm{Ab}$ response and strength of protection.

Results: Independent of adjuvants and immunization route, on average $87 \%$ of the M2e-MAP-induced Abs were specific for M2e peptide and a variable fraction of these M2e(pep)-specific Abs (average 15\%) cross-reacted with presumably native M2e expressed by M2-transfected cells. The titer of these cross-reactive M2e(pep-nat)-specific Abs in sera of parenterally immunized mice displayed a sigmoidal relation to level of protection, with $\mathrm{EC}_{50}$ of $\sim 20$ $\mu \mathrm{g} \mathrm{Ab} / \mathrm{ml}$ serum, though experiments with passive M2e(pep-nat) Abs indicated that serum Abs did not fully account for protection in parenterally vaccinated mice, particularly in upper airways. Intranasal vaccination engendered stronger protection and a higher proportion of $\mathrm{G} 2 \mathrm{a}$ Abs than parenteral vaccination, and the strength of protection failed to correlate with M2e(pep-nat)-specific serum Ab titers, suggesting a role of airway-associated immunity in protection of intranasally vaccinated mice. Intranasal administration of M2e-MAP without adjuvant engendered no response but coadministration with infectious IAV slightly enhanced the M2e(pep-nat) Ab response and protection compared to vaccination with IAV or adjuvanted M2e-MAP alone.

Conclusion: M2e-MAP is an effective immunogen as $\sim 15 \%$ of the total M2e-MAP-induced Ab response is of desired specificity. While $M 2 e$ (pep-nat)-specific serum Abs have an important role in restricting virus replication in trachea and lung, M2e-specific T cells and/or locally produced Abs contribute to protection in upper airways. Intranasal vaccination is preferable to parenteral vaccination, presumably because of induction of local protective immunity by the former route. Intranasal coadministration of M2e-MAP with infectious IAV merits further investigation in view of its potential applicability to human vaccination with live attenuated IAV.
\end{abstract}




\section{Background}

Two types of influenza A virus (IAV) vaccines are currently used: 1) non-infectious preparations of detergent-disrupted virus particles or purified viral glycoproteins, hemagglutinin (HA) and neuraminidase (NA), which are licensed for all ages $\geq 0.5 \mathrm{y}$ and 2 ) live attenuated, temperature sensitive and cold-adapted IAV, which are currently licensed for vaccination of 5 to $49 \mathrm{y}$ old subjects [1]. Both vaccines attempt to engender strong $\mathrm{Ab}$ responses to HA and NA, and can be 70-90\% effective in preventing IAVinduced illness [1]. Still, current vaccines have shortcomings: First, the viral glycoproteins are highly variable targets and change from year to year. Thus, the efficacy of current vaccines depends greatly on how well the glycoproteins of the vaccine strains, which must be selected 89 months prior to the influenza season, match those of the actual circulating epidemic strain. A mismatch is likely to cause a decrease in protective efficacy. Second, the presently licensed inactivated vaccines have relatively low $(\leq 50 \%)$, if any [2], protective efficacy in the elderly $(\geq 60$ $y$ ). This is a problem because elderly people are at high risk for severe disease, and 90\% of influenza-associated mortality in the U.S. (on average 30,000/year) occurs in this segment of the population [1]. Third, newborns $(\leq 0.5$ y), who also are at high risk for severe disease and are usually protected by passively acquired maternal Abs [3], may be with no or low protection in case of a major mismatch between vaccine and circulating IAV strains. These shortcomings of current vaccines could be lessened by a vaccine or vaccine adjunct that engendered protective Abs against viral structures of low or no variability, and thereby provided a constant level of long lasting resistance against IAV infection, independent of the glycoprotein makeup of circulating IAV strains.

The ectodomain of matrix protein 2 (M2e) is a promising candidate for a broadly protective IAV vaccine as M2e underwent remarkably little sequence variation amongst human IAV strains isolated between 1918 to 2005, and M2e-specific Abs have been shown to display significant protective activity in animal models [4-11]. Most importantly, however, M2e-specific Ab titers are very low or undetectable in human sera, suggesting that current vaccines or recovery from natural infection fail to induce significant M2e-specific Ab responses [12-14]. Thus, humans are currently without significant M2e-specific Ab-mediated protection. Based on these premises, various $\mathrm{M} 2 \mathrm{e}-$ specific vaccine constructs have been explored in recent years and tested for immunogenicity and protective activity in preclinical models [4-6,8,9,15-18]. In view of the relatively small size of $\mathrm{M} 2 \mathrm{e}$ (23aa), we chose to develop a synthetic multiple antigenic peptide (MAP) vaccine. The latter consists of four M2e and two helper T cell peptides linked to a linear scaffold peptide [17]. In a previous study, we showed that immunization of mice with M2e-
MAP plus cholera toxin (CT) and immunostimulatory oligodeoxynucleotide (ODN) by the i.n. route induced significant M2e-specific Ab responses and protection [17]. Here, we report studies in which we investigated the roles of adjuvant and route of vaccine administration on titer and composition of the M2e-specific $A b$ response and strength of protection.

\section{Results \\ Specificity of the M2e-MAP-induced $A b$ response}

M2e-MAP consists of a scaffold peptide to which M2eand Th determinant peptides are covalently attached (Fig 1 ). Each of these peptides or combinations thereof may serve as target for MAP-induced Abs. We were interested in learning what fraction of the total M2e-MAP-induced Ab response was specific for $M 2 e$ peptide and what fraction of the M2e-peptide-specific Abs was capable of binding to native tetrameric $\mathrm{M} 2 e$. The latter was of particular interest because only Abs capable of binding to native tetrameric M2e would be expected to display protective activity. To measure the total M2e-MAP-specific response, we tested sera of M2e-MAP-immunized mice by ELISA against wells coated with the M2e-MAP used for immunization as specific and uncoated (BSA-blocked) wells as non-specific (background) immunosorbents. M2e-peptide (pep)-specific Ab titers were measured by using Cys-M2e coated wells as specific and Cys-bb-coated wells as non-specific immunosorbents. Abs specific for cell-expressed, presumably native, tetrameric M2e were measured by using HeLaM2 cells as specific and HeLa-C10 cells as non-specific immunosorbents. Since the latter Abs are a fraction of the

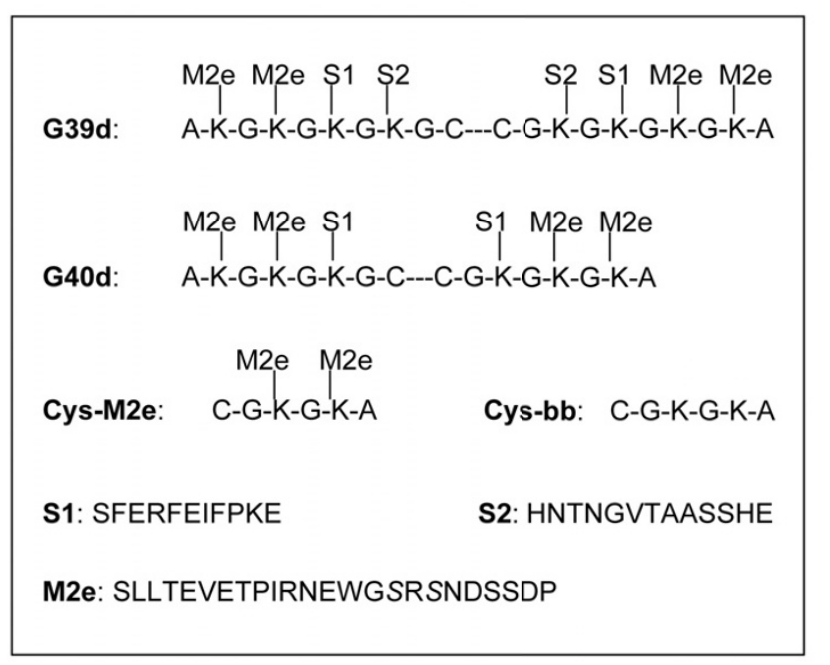

\section{Figure I}

Composition of MAPs. The amino acid (aa) composition of the scaffolds of G39d and G40d is shown in single letter code. The triple dash in the scaffolds denotes the disulfide bond between adjacent cysteins. SI and S2 are helper T cell peptides and $\mathrm{M} 2 \mathrm{e}$ the $24 \mathrm{~N}$-terminal aa of $\mathrm{M} 2$, linked through their $\mathrm{C}$-terminal aa to the indicated lysines of the scaffold peptides. 
M2e(pep)-specific Abs, they will be referred to as M2e(pep-nat)-specific to distinguish them from Abs that react with native cell-expressed M2e but not with M2e peptide, an $\mathrm{Ab}$ population detected in mice that have recovered from repetitive IAV infections [13]. The M2especific MAb 14C2-S1-4, which binds with comparable efficacy to all three specific immunosorbents under the present assay conditions (Fig 2A), was used as a standard to quantify the ELISA data.

Fig 2B shows results from an experiment in which four groups of mice were immunized three times by i.n. or s.c. routes with the M2e-MAP G40d together with the immunostimulatory oligodeoxynucleotide 1826 (ODN) or ODN and cholera toxin (CT). Ab titers were measured in pooled plasma samples (5 mice/group) collected three weeks after secondary and tertiary immunization. It is evident that M2e(pep)-specific Abs accounted for the majority $(79 \% \pm 18 \%$, SD) of the total G40d-specific response (defined in each sample as 100\%). M2e(pep-nat)-specific Abs made up a smaller and more variable fraction $(10 \% \pm$ $8 \%, \mathrm{SD})$ of the total G40d-specific response. In most experiments, only M2e(pep)- and M2e(pep-nat)-specific $\mathrm{Ab}$ titers were determined. Taking 27 distinct vaccination groups into account, M2e(pep-nat)-specific Ab titers ranged from $\sim 1 \%$ to essentially $100 \%$ of the M2e(pep)specific $A b$ titers and accounted on average for $14.5 \%$ (geometric mean, GM) of the M2e(pep)-specific response (Fig 2C). The various immunization protocols employed here had no significant effect on the size of the M2e(pepnat)-specific $\mathrm{Ab}$ fraction (Fig 2C).

Taken together, the results indicated that the majority of the M2e-MAP-induced Abs were M2e(pep)-specific, and that a variable fraction of these Abs crossreacted with $\mathrm{M} 2$ expressed by HeLa-M2 cells, i.e. displayed M2e(pep-nat)specificity.

\section{Roles of adjuvant and immunization route on $A b$ response and protection}

In our previous study [17], we had shown that mice vaccinated with M2e-MAP, ODN and CT by the i.n. route exhibited significant resistance to total respiratory tract infection with IAV. Here, we wanted to determine whether route of vaccination and use of CT as adjuvant made a significant contribution to protection. To this end, mice were immunized three times at 4-5 week intervals with M2eMAP plus ODN with or without CT by i.n. or s.c. (tail base) routes. M2e-specific Ab titers in plasma (pools of 45 mice per group) collected three weeks after the third immunization were determined and mice challenged 710 days later by nasal infection with X31. Results from four independent repeat vaccination and challenge experiments are compiled in Fig 3.

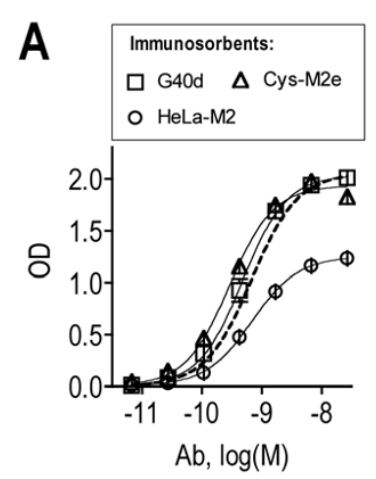

B
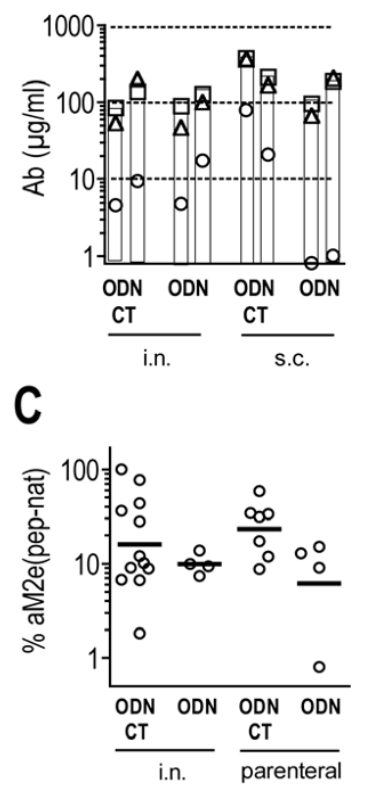

Figure 2

Fine specificity of the M2e-MAP induced Ab response. A. MAb 14C2$\mathrm{SI}-4$, which was used in all assays for quantification of serum $A b$ titers, was tested in ELISA against M2e-MAP Gd40 (squares), Cys-M2e (triangles) and HeLa-M2 (circles) as described in the method section, using the same reagents and incubation times for each assay. The mean OD ( \pm SEM) above background of six replicates at each Ab dilution are shown. The three sigmoidal titration curves have similar EC50 values ( -9.3 vs G40d, -9.5 vs Cys-M2e, -9.2 vs HeLaM2). To further demonstrate the similarity between the three titration curves, OD values measured against HeLa-M2 were multiplied by 1.65 to generated the stipulated curve. A representative assay is shown. B. Pooled plasma samples (5 mice/group), obtained 3 wks after second (left column) and third (right column) immunization, were tested by ELISA for M2e-MAP- (squares), M2e(pep)- (triangles) and M2e(pep-nat)-specific (circles) Ab titers as described in the method section. The mice had been immunized with $3 \mu \mathrm{g}$ M2e-MAP G40d and adjuvants by i.n. or s.c. routes as indicated below the $\mathrm{x}$ axis. Each symbol shows the mean serum $A b$ concentration determined in each sample by $2-3$ independent assays. Data from a single vaccination experiment are shown. C. The fraction of M2e(pep-nat)-specific Abs is expressed as percent of the M2e(pep)-specific Ab concentration within each sample. Each dot indicates the \% of anti-M2e(pepnat) per group of 3-5 mice immunized by one of the protocols indicated below the $x$ axis. In most groups, samples from secondary and tertiary responses were tested, and the mean \% of these is shown. Horizontal bars indicate the geometric means within a vaccination protocol. Data from 12 independent vaccination experiments are shown. Groups immunized by different protocols did not differ significantly (ANOVA) with regards to percentage of anti-M2e(pepnat)-specific Abs.

As shown in Fig 3A, M2e(pep)- and M2e(pep-nat)-specific $\mathrm{Ab}$ titers were slightly higher in mice vaccinated with ODN and CT by the s.c. route than in the other vaccina- 


\section{A. Ab titers in serum}
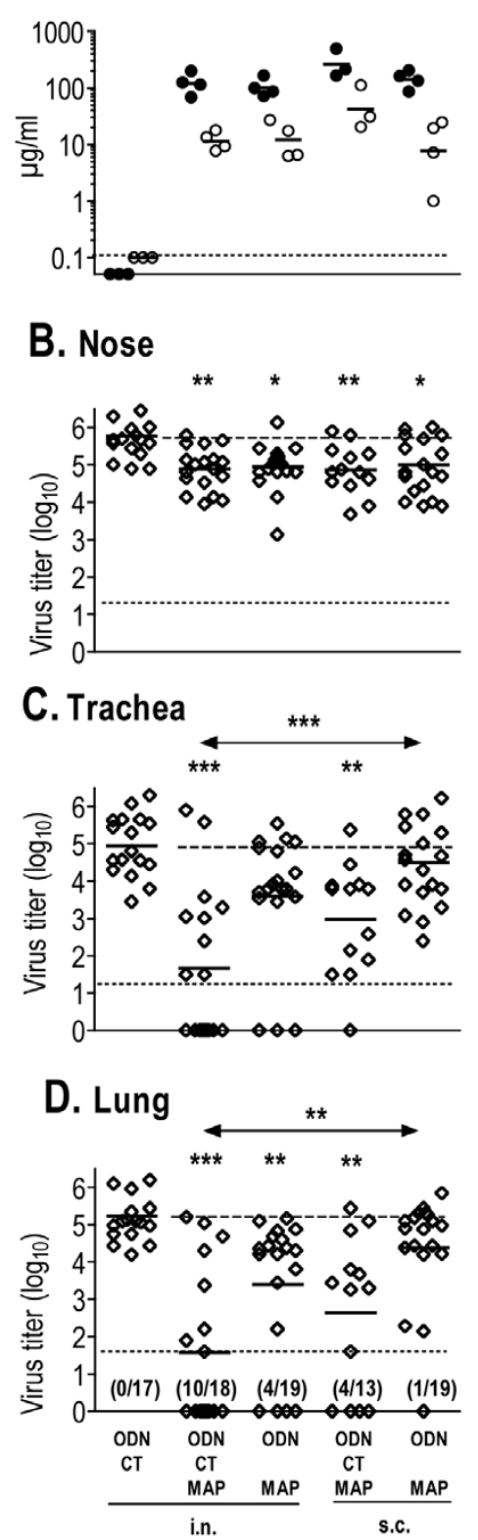

Figure 3

$A b$ response and protection after various modes of vaccination. $A$. $\mathrm{BALB} / \mathrm{c}$ mice were vaccinated three times at 4-5 week intervals with $3 \mu \mathrm{g} \mathrm{M} 2 \mathrm{e}-$ MAP (two experiments G39d, two G40d) and the indicated adjuvants (see bottom of figure) by i.n. or s.c. route. Mice were bled 3 weeks after the third immunization. Pooled plasma samples (3-5 mice/pool) were tested by ELISA for M2e(pep)- (dots) and M2e(pep-nat)-specific (circles) Ab titers. Horizontal bars indicate GMTs within each set. Data from four independent vaccination experiments are shown. B, C, D. 7-10 days after the third vaccination, mice were challenged by i.n. inoculation of $5 \mu \mathrm{I} \times 3 \mathrm{I}\left(1000 \mathrm{TCID}_{50} /\right.$ mouse). Five days later, nose, trachea and lung were tested for virus titer. Each symbol indicates the virus titer of an individual mouse. Horizontal bars indicate the GMT within each vaccination set. Dashed (top) and stipulated (bottom) horizontal lines indicate the mean virus titer of control mice and threshold of virus detection, respectively. Tissues with undetectable virus were assumed to be virus free. Data were analyzed by non-parametric ANOVA and Dunn's Multiple Comparison post test. M2e-MAP vaccination groups with statistically significant reduction in virus titer compared to the control group are indicated by asterisks right above the group and statistical differences between M2e-MAP vaccination groups by asterisks above two-sided arrows: $\mathrm{p}<0.05\left(^{(*)}, \mathrm{p}<0.01(* *), \mathrm{p}<0.001(* * *)\right.$. tion groups. Although this difference was not significant (by ANOVA) in the four experiments shown in Fig 3A, it was significant when $\mathrm{Ab}$ titers after the second immunization were analyzed and additional vaccination experi-

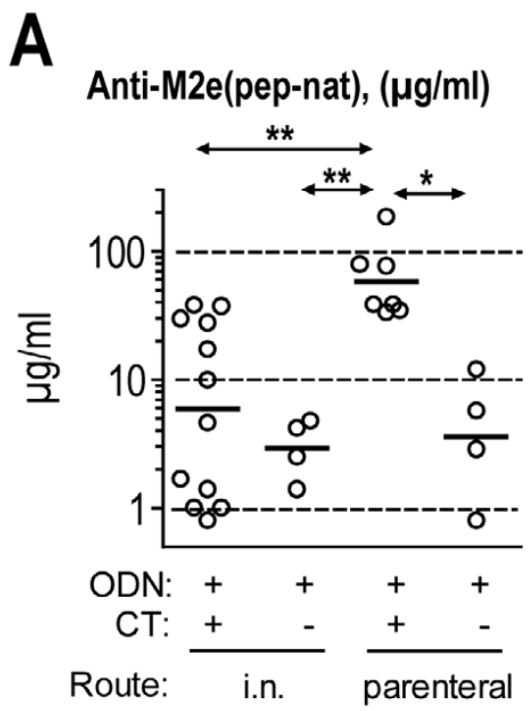

B

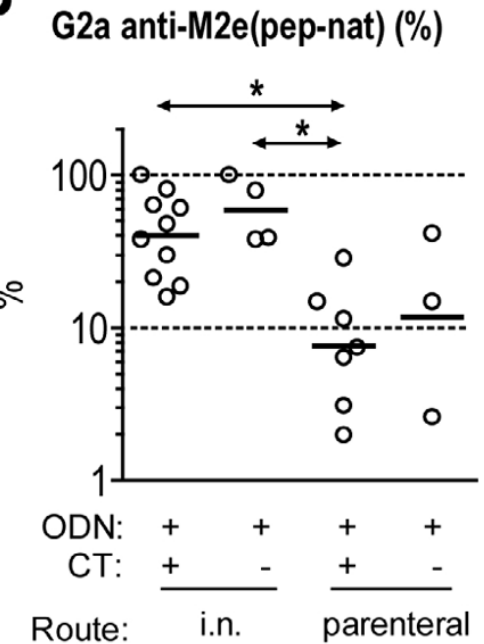

Figure 4

Effect of immunization protocol on size and G2a content of the M2e(pep-nat)-specific Ab response. A. M2e(pep-nat)-specific Ab titers in pooled plasma samples collected three weeks after second immunization from mice vaccinated with M2e-MAP according to the protocol indicated below the $x$ axis. Each dot shows the titer of pooled plasma from 3-5 mice. Horizontal bars indicate the GMTs of groups within a given vaccination protocol. Data were analyzed by ANOVA and Tukey's Multiple Comparison post test. Statistically significant differences between group are indicated by asterisks above twosided arrows: $\mathrm{p}<0.05(*), \mathrm{p}<0.01$ (**). B. Pooled plasma from 4-5 mice/group collected three weeks after second and third immunization were tested for concentration of $C_{\kappa}$ - (total) and $\gamma 2 a$-expressing M2e(pep-nat)-specific Ab titers and the latter were expressed as percentage of the former. In groups that were immunized three times, the mean percentage of G2a after $2^{\text {nd }}$ and $3^{\text {rd }}$ immunization is shown. Groups with low M2e(pep-nat)-specific Ab titers that did not permit detection of $G 2$ at $<5 \%$ were excluded from the analysis. Horizontal bars show GMTs within distinct immunization protocols. Data were analyzed by ANOVA and Tukey's Multiple Comparison post test and marked as in A. 
ments taken into account (Fig 4A). Thus, in the presence of ODN, CT strongly enhanced the Ab response upon parenteral though not i.n. vaccination.

The strength of protection was assessed by i.n. inoculation of mice with $5 \mu \mathrm{l}\left(1000 \mathrm{TCID}_{50}\right)$ of X31 virus. This challenge induces an infection that is initially confined to the nasal epithelium and from there spreads in non-immune mice within a few days into the lower respiratory tract. Five days after challenge, mice were euthanized and virus titers determined in nose, trachea (together with extrapulmonary bronchi) and lung. As shown in Fig 3B-D, the infection had spread by this time in all control mice (immunized with adjuvant only) into trachea and lung. Compared to the control group, all M2e-MAP vaccination groups showed significant restriction of similar strength against virus growth in the nose (Fig 3B). The groups differed, however, with regards to resistance against descending infection. The least resistance was seen in mice vaccinated with M2e-MAP and ODN by the s.c. route and in fact did not differ significantly from the control group. The strongest and most significant resistance was seen in mice vaccinated with ODN and CT by the i.n. route. The other two vaccination groups (i.n. with ODN but without CT and s.c. with ODN and CT) displayed intermediate and similar levels of protection.

Taken together, the results indicated that CT significantly enhanced the systemic $A b$ response when administered together with ODN by a parenteral route and strengthened protection both upon parenteral and i.n. vaccination. Furthermore, independent of the adjuvants used, the i.n. route of vaccination engendered stronger protection than parenteral vaccination. However, the relationship between strength of protection and M2e-specific serum $\mathrm{Ab}$ titer was not clear. For instance, mice vaccinated with M2e-MAP and ODN by s.c. route displayed significantly weaker resistance against descending infection than mice immunized with M2e-MAP, ODN and CT by i.n. route, in spite of similar serum Ab titers. This was unexpected in view of previous findings showing that protection could be transferred with serum from M2e-immune to naive mice $[4-6,8,9]$.

\section{Relation between M2e-specific serum Ab titers and protection}

The absence of a clear relation between serum Ab titer and strength of protection suggested that the concentration of Cr-positive M2e-specific Abs in serum (biotinylated anti$\mathrm{C} \kappa$ was used for measurement of Ab titers) was not the sole determinant of protection. Although $\lambda$ light chains are expressed only by $\sim 5 \%$ of Abs in the BALB/c mouse, they may be expressed at higher frequency in responses of some specificities. We therefore tested selected serum samples for $\lambda$-positive M2e-specific Abs but found no evidence for the substantial use of $\lambda$ light chains in the M2especific Ab response (data not shown). Thus, differences in the fine specificity, avidity or heavy chain isotype of M2e-specific serum Abs or of immune phenomena that are mostly confined to the respiratory tract and poorly reflected in serum could make significant contributions to protection. To further explore these possibilities, we analyzed the relation between M2e-specific serum Ab titers and strength of protection in the above and additional groups of mice that had been vaccinated with M2e-MAP, challenged by localized nasal infection with the same dose of X31 virus and analyzed for virus titer five days later. To detect potential contributions of respiratory tractassociated immune phenomena, which may be induced preferentially by i.n. immunization, groups vaccinated by i.n. and parenteral routes were analyzed separately. The reduction in virus titer (on $\log _{10}$ basis) in M2e-MAP immunized groups compared to the control group (adjuvant only) of the given immunization experiment was used as measure of strength of protection. Tissues with undetectable virus (threshold of $10 \operatorname{EID}_{50}$ for nose and trachea and $10^{1.3}$ for lung) were assumed to be virus-free.

Table I: Correlation between M2e-specific serum Ab titer and reduction of virus titer in various sites of the respiratory tract after parenteral and i.n. immunization.

\begin{tabular}{|c|c|c|c|c|c|c|}
\hline \multirow{3}{*}{$\begin{array}{l}\text { Specificity/lsotype } \\
\text { of anti-M2e Abs }\end{array}$} & \multicolumn{6}{|c|}{ Spearman correlation coefficient $r(p)$} \\
\hline & \multicolumn{3}{|c|}{ parenteral vaccination } & \multicolumn{3}{|c|}{ i.n. vaccination } \\
\hline & Nose & Trachea & Lung & Nose & Trachea & Lung \\
\hline M2e(pep) & 0.07 & -0.03 & 0.18 & 0.2 & 0.24 & 0.02 \\
\hline M2e(pep-nat) & 0.96 (***) & $0.82(* *)$ & $0.8(* *)$ & -0.38 & -0.27 & -0.31 \\
\hline M2e(pep-nat) G2a & 0.56 & 0.51 & $0.75(*)$ & -0.43 & -0.30 & -0.35 \\
\hline
\end{tabular}

Mean (4-5 mice/group) M2e-specific serum Ab titers 7-10 days before challenge with $\mathrm{X} 3 \mathrm{I}$ virus $\left(5 \mu \mathrm{l}, 10^{3} \mathrm{TCID}_{50}\right)$ were analyzed for correlation with mean reduction (compared to control group) of virus titers in nose, trachea and lung. Included in the analysis are 9 groups of mice immunized with M2e-MAP by a parenteral route (s.c., i.m., i.p.) and 14 groups immunized by the i.n. route. Statistical significance of correlation (Spearman $r$, non parametric) is indicated by asterisk: $(*): p<0.05,(* *): p=0.01,(* * *): p=0.002$. 
As shown in Table 1, Cк-positive M2e(pep)-specific serum $\mathrm{Ab}$ titers showed no significant correlation with strength of protection, both after i.n. and parenteral immunization. By contrast, highly significant correlations were seen between M2e(pep-nat)-specific Ab titers and protection after parenteral though not i.n. immunization. These findings indicated, firstly, that only Abs capable of reacting with native cell-expressed $\mathrm{M} 2 \mathrm{e}$ played a role in protection. Since M2e(pep-nat)-specific Abs are a subpopulation of the M2e(pep) specific response, the absence of correlation between M2e(pep)-specific Ab titers and protection is apparently a consequence of the substantial variation between groups in the proportion of M2e(pep-nat)specific Abs within the total M2e(pep)-specific response (Fig 2C). Second, the absence of correlation between $\mathrm{M} 2 \mathrm{e}$ (pep-nat)-specific serum Ab titers and protection in mice immunized by the i.n. route indicated that $M 2 e$ (pepnat)-specific serum Abs were not the sole effectors of protection; conceivably, M2e-specific Abs produced in airway tissues, whose titers are inadequately reflected in serum, or M2e-specific T cells may contribute to protection.

Abs of G2a isotype have often been found to display higher activity in vivo than Abs of other IgG isotypes. This has been attributed to the ability IgG2a to interact with all three activating IgG Fc receptors, Fc $\gamma$ RI, Fc $\gamma$ RIII and most notably Fc $\gamma$ RIV, for which G2a is the preferred isotype $[19,20]$. In agreement with this, naive mice, passively protected with the G2a isotype switch variant of $\mathrm{mAb}$ $14 \mathrm{C} 2$, showed significantly less weight loss $(\mathrm{p}<0.05)$ and less mortality $(\mathrm{p}=0.08)$ than mice passively protected with the same dose of mAb $14 \mathrm{C} 2$ of $\mathrm{G} 1$ or G2b isotype

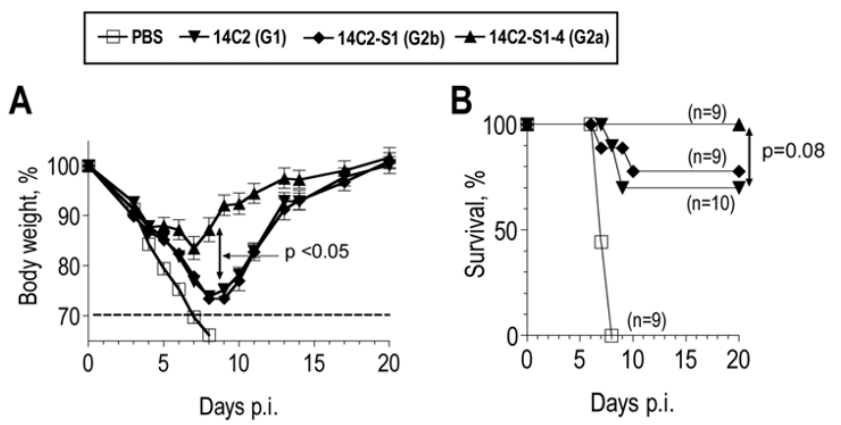

\section{Figure 5}

Role of heavy chain isotype in protection. Naive $B A L B / c$ mice were injected i.p. with $10 \mu \mathrm{g} \mathrm{mAb}$ | $4 \mathrm{C} 2$ of $\mathrm{GI}$ (triangles pointing down), G2b (diamonds) or G2a (triangles pointing up) isotype. The control group (open squares) received PBS i.p. One day later, mice were exposed to a total respiratory tract challenge with PR8 $\left(4 \mathrm{LD}_{50}\right.$ in $\left.50 \mu \mathrm{l}\right)$ and monitored for weight loss. Pooled data from two independent experiments are shown, each performed with 4-5 mice/group. A. Symbols show mean \% body weight and SEM (relative to day 0) of 9-10 mice/group. Differences between treatment groups were tested for statistical significance at individual days. Mice treated with G2a showed significantly $(p<0,05$, ANOVA) less weight loss than those treated with GI or G2b at days 6 to I 3 p.i. B. Survival. Death was defined as $>30 \%$ weight loss, at which stage mice were euthanized. Differences between survival curves were tested for statistical significance by log rank test.
(Fig 5). Therefore, we determined also titers of M2e(pepnat)-specific G2a in sera, hoping Abs of this isotype may show an improved correlation with protection. However, the contrary was the case, possibly because positive effects on correlation due to the increased protective activity of G2a were outweighed by negative effects on correlation due to the variability in the proportion of G2a within the total M2e(pep-nat) response (Fig 4B). It is possible also that the G2a isotype provides a smaller advantage over other isotypes in inhibition of a descending infection by $\mathrm{X} 31$ virus - the endpoint used for the data in table 1 than in reduction of morbidity and mortality after total respiratory tract challenge with PR8 - the endpoint used in the comparison of the isotype switch variants (Fig 5). An interesting observation resulting from this analysis was that i.n. vaccination engendered an $A b$ response with a significantly larger proportion of G2a (GM: 45\%) than parenteral immunization (GM: 8\%), independent of the adjuvants used (Fig 4B).

In view of the significant correlation between total M2e(pep-nat)-specific serum Ab titer and protection after parenteral immunization, we subjected the data to linear and non-linear regression analysis. Linear regression analysis showed a poor fit between $\mathrm{Ab}$ titer and protection, with $\mathrm{R}^{2}$ values of $0.45,0.36$ and 0.37 for protection in nose, trachea and lung, respectively, though elimination of one outlier group with the highest serum $\mathrm{Ab}$ titer yielded linear regressions with $\mathrm{R}^{2}$ and $(\mathrm{p})$ values of 0.94 $(<0.0001), 0.66(0.014)$ and $0.78(0.0039)$ for protection in nose, trachea and lung, respectively. However, without exclusion of any data, the relations between $\mathrm{Ab}$ titers and protection could be described by sigmoidal curves that exhibited $\mathrm{R}^{2}$ values of 0.79 for nose and lung and 0.65 for trachea (Fig 6A). They indicated that M2e-specific protection after parenteral immunization exhibited an upper boundary and half-maximm protection was achieved in each site of the respiratory tract at the serum $\mathrm{Ab}$ concentration of $\sim 20 \mu \mathrm{g} / \mathrm{ml}$. By contrast, in i.n. vaccinated mice, there was no obvious relation between serum $A b$ titer and protection. Indeed, significant protection was seen in many mice with serum $\mathrm{Ab}$ titers that were completely non-protective in parenterally vaccinated mice. This is demonstrated in Fig. 6B and 6C, which display the data from individual i.n. (filled symbols) and parenterally vaccinated (open symbols and deduced sigmoidal curve) groups for protection in the nose and lung, respectively. Apparently, vaccination by the i.n. route was capable of inducing potent protective activities other than those mediated by M2e-specific serum Abs.

\section{$A b$ response and protection after i.n. administration of M2e-MAP together with infectious virus}

Recovery from respiratory tract infection has been shown to result in optimal protection [21]. This is generally 

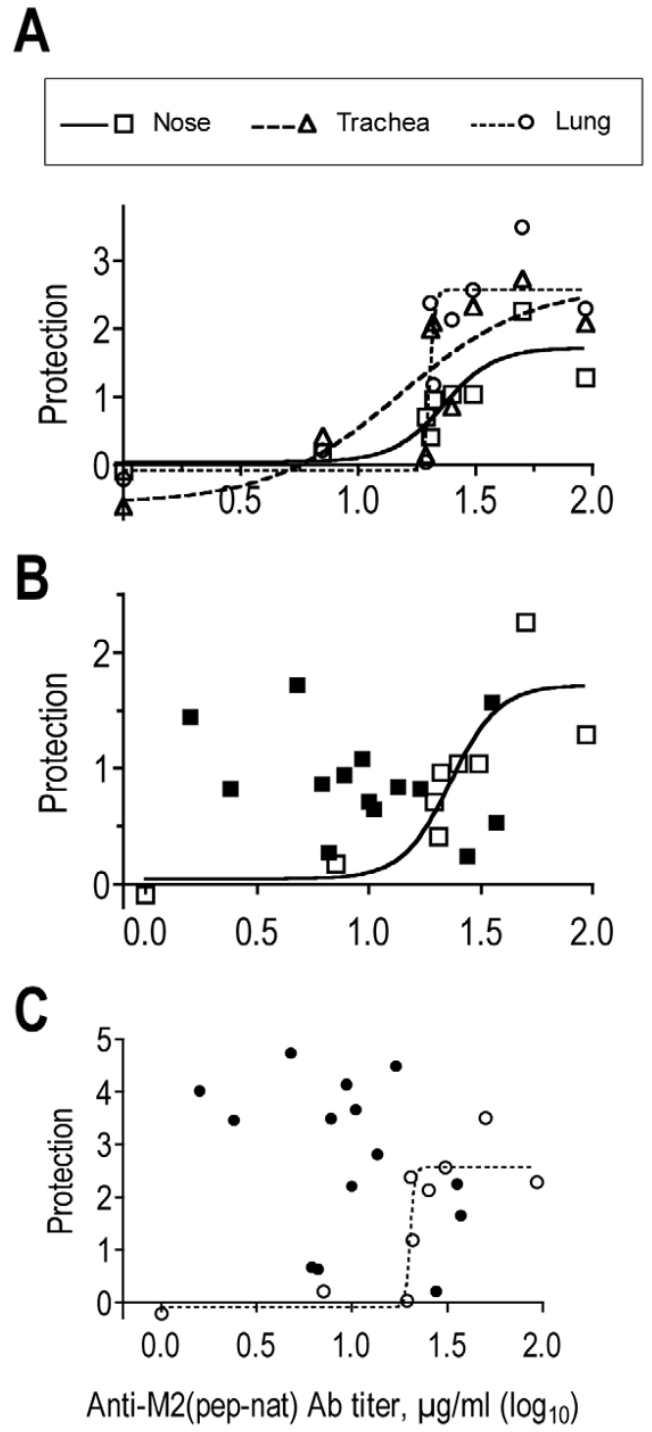

Figure 6

Relation between M2e(pep-nat)-specific Ab titer and protection against virus challenge. $C \kappa$-positive M2e(pep-nat)-specific Ab titers were determined in pooled plasma (3-5 mice/group) collected 7-10 days before challenge of mice by localized nasal infection $\left(5 \mu \mathrm{I} X 31,1000 \mathrm{TCID}_{50}\right)$. Five days after challenge, virus titers were determined in nose, trachea and lung of individual mice and the group average was determined. The average reduction in virus titer on $\log _{10}$ basis compared to the control group (immunized with adjuvant alone) was taken as measure of strength of protection ( $y$ axis). A. Protection in nose (squares), trachea (triangles) and lung (circles) from nine groups of mice immunized by parenteral route is plotted against the M2e(pep-nat)-specific serum $A b$ titer ( $x$ axis). Non-linear regression analysis yielded sigmoidal regression curves with $R^{2}$ of 0.79 for nose (stipulated) and lung (continuous) and of 0.65 for trachea (dashed). B. Serum Ab titers and protection in nose observed in mice immunized by the i.n. route (filled squares) are plotted

together with the regression line and corresponding data points (open squares) from mice immunized by parenteral route (as in $A$ ). C. Serum $A b$ titers and protection in lung of mice immunized by i.n. route (filled circles) are plotted together with the regression line and corresponding data points (open circles) from mice after parenteral immunization (as in A).

attributed to the combined effects of strong local and systemic $\mathrm{T}$ and $\mathrm{B}$ cell responses against several viral proteins. Since infection induces only a poor M2e-specific Ab response [13], we wondered whether infection-induced protection could be further strengthened by concomitant immunization with M2e-MAP. This was tested by i.n. administration of a sublethal dose of PR8, either alone or together with $3 \mu \mathrm{g}$ M2e-MAP. Both groups of mice developed a primary infection from which they recovered. Four weeks later, the mice were inoculated i.n. with PR8-Seq14 $\left(200 \mathrm{TCID}_{50}\right)$, again with or without M2e-MAP. Other groups of mice were inoculated twice by the i.n. route with A) ODN and CT (negative control), B) M2e-MAP (3 $\mu \mathrm{g} /$ dose) in PBS without adjuvant, C) M2e-MAP with ODN and CT (positive control) or D) $5 \mu \mathrm{g}$ purified uvinactivated PR8 virus. We decided on this dosage of inactivated virus, which contains $\sim 10^{6}$ times the amount of virus present in $200 \mathrm{TCID}_{50}$, to compensate for the lack of replication in vivo. Plasma samples were collected three weeks after the boost, pooled within each group, and tested by ELISA against M2e peptide and HeLa-M2.

Fig 7A shows Ab titers from three independent vaccination experiments. No M2e-specific Abs were detected in sera of mice immunized with M2e-MAP without adjuvant or with inactivated virus. The former shows that M2e-MAP is not immunogenic in the absence of adjuvant and the latter that $\mathrm{M} 2$ - a minor viral structural protein that makes up only $\sim 0.2 \%$ of the total protein mass of virus particles [22] - is not immunogenic in the context of a large dose of mature virus particles. Note, however, that mice immunized twice with inactivated virus made a strong HA-specific $A b$ response (data not shown). M2e-specific $A b$ responses were seen in all other groups. However, they differed in titer and fine specificity in that mice immunized with M2e-MAP plus adjuvant displayed higher $\mathrm{Ab}$ titers against M2e peptide than HeLa-M2 while, as shown previously [13], the reverse was the case for mice immunized by infection. Importantly, the highest $\mathrm{Ab}$ titers against HeLa-M2 were seen in mice immunized concomitantly with infectious virus and M2e-MAP, and the majority of these Abs appeared to display M2e(pep-nat)specificity.

Seven to fourteen days after the second immunization, mice from two vaccination experiments were challenged by i.n. instillation of $50 \mu \mathrm{l}$ of X31. This mode of challenge initiates an infection throughout the respiratory tract (nose, trachea, pulmonary airways) and was chosen in preference of the localized nasal infection because the latter did not descend within five days into the lower respiratory tract in infection-immunized mice (our unpublished observation) and therefore was unsuitable for revealing differences between the groups immunized by infection with/without M2e-MAP. Three days after total respiratory tract infection, mice were euthanized and virus titers in nose, trachea and lung determined. Compared to control mice (adjuvant alone), significant reductions in virus titers were seen in mice immunized with 
A
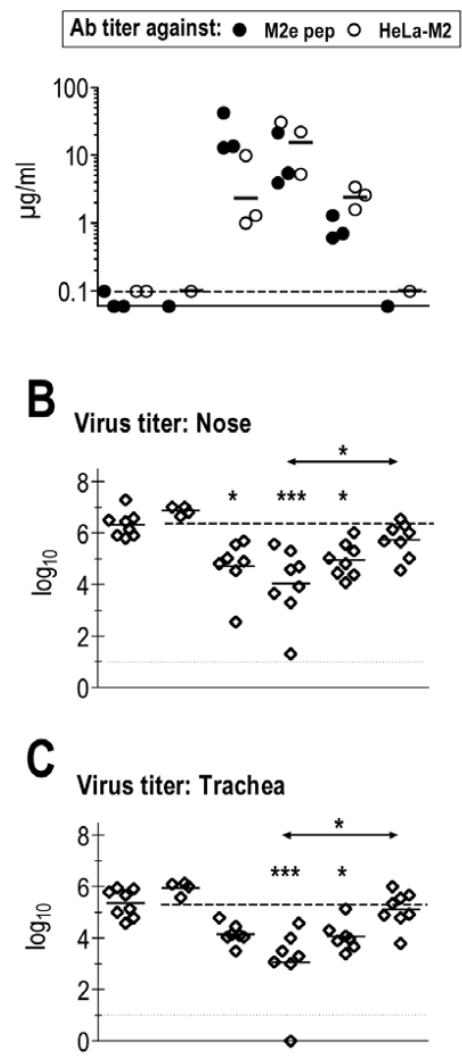

Dirus titer: Lung

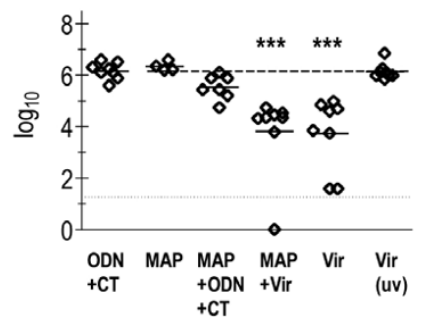

Figure 7

Immunization with the combination of infectious virus and M2eMAP. BALB/c mice were immunized twice ( 4 week interval) by the i.n. route with the components listed at the bottom of the figure. Dosage/injection ( 50 $\mu \mathrm{l})$ : M2e-MAP G39d $(3 \mu \mathrm{g})$, ODN $(3 \mu \mathrm{g})$, CT $(0.5 \mu \mathrm{g})$, Vir $\left(150-200\right.$ TCID $_{50}$ of PR8 for primary and of Seql 4 for secondary immunization). Vir(uv) (5 $\mu \mathrm{g}$ of purified uv-inactivated PR8, <I TCID 5 ). Plasma was collected three weeks after second immunization and pooled within groups. A. Ab titer measured by ELISA against M2e peptide (closed circles) and HeLa-M2 (open circles) in pooled plasma samples of groups of 3-4 mice from three independent vaccination experiments. Bars indicate the GMTs. The stipulated horizontal line indicates the threshold of detection of Ab titers against HeLa-M2. B, C, D. Four weeks after the second immunization, mice from two vaccination experiments were challenged by i.n. inoculation of $50 \mu \mathrm{I} X 3 \mathrm{I}$, which initiates an infection throughout the entire respiratory tract. Virus titers in nose, trachea and lung were determined three days later. Each symbol indicates the total virus titer (TCID $D_{5}$ from an individual mouse in the nose (B), trachea (C) and lung (D). Bars indicate GMTs. The data were analyzed by non-parametric ANOVA and Dunn's Multiple Comparison Test. Statistical significance between experimental and control groups and between experimental groups is indicated by asterisks above each column and above two-sided arrows, respectively: $\mathrm{p}<0.05(*) ; \mathrm{p}<$ $0.01(* *)$.
M2e-MAP plus adjuvant, M2e-MAP plus infectious virus or infectious virus alone, but the two infection-immunized groups showed stronger protection in the lung than the M2e-MAP/adjuvant-immunized group. Comparison between the infection-immunized groups indicated a slight increase in resistance against virus replication in the nose and trachea in mice that had been co-immunized with M2e-MAP, although the difference did not reach statistical significance with the few mice used in these experiments.

Taken together, the results indicated that combined vaccination with M2e-MAP and infectious virus may improve the induction of HeLa-M2-reactive Abs and slightly enhance protection in nose and trachea compared to vaccination with infectious virus or M2e-MAP alone.

\section{Discussion}

\section{Relation between $A b$ specificity, titer and protection}

We found that the concentration of M2e(pep-nat)-specific Abs in sera of parenterally vaccinated mice correlated with strength of protection (Table 1). This is consistent with previous studies showing that protection can be transferred to naive mice by passive M2e-specific Abs $[10,11,17]$ and antisera $[4-6,8,9]$. It is consistent also with the generally held view that M2e-specific Abs mediate protection by reaction with M2e expressed in the plasma membrane of infected host cells. By contrast, M2e(pep)specific $\mathrm{Ab}$ titers showed no correlation with protection, in spite of the fact that the M2e(pep-nat)-specific Abs are a fraction of the larger M2e(pep)-specific $A b$ response (Table 1). This lack of correlation between M2e(pep) Ab titer and protection appears to be a consequence of the large variability of the $\mathrm{M} 2 \mathrm{e}$ (pep-nat)-fraction within the M2e(pep) response (Fig 2C). The reason for this variability is not known. It could be due to a low frequency of $\mathrm{M} 2 \mathrm{e}$ (pep)- and M2e(pep-nat)-specific B cells within the naive $\mathrm{B}$ cell repertoire, which may result, for stochastic reasons, in large differences in the composition of this response between individuals and even pooled sera from 3-5 animals, as tested here. A low precursor B cell frequency is consistent with our previous finding that seven M2e(pep-nat)-specific hybridomas isolated from three mice all expressed a highly restricted heavy chain variable region (formed by recombination of the same $\mathrm{V}_{\mathrm{H}}$, D and J gene segments) in association with only two distinct $V_{L}$ genes [23]. The M2e(pep)-specific response has not been analyzed at the clonal level but may be equally restricted. Because of this variability, the protective M2e(pep-nat)specific Ab titers cannot be extrapolated from M2e(pep)specific $A b$ titers and must be measured specifically.

Given the importance of M2e(pep-nat)-specific Abs in protection, the selective promotion of this Ab population by a M2e vaccine would be advantageous. This may be 
achieved by development of a more effective vaccine construct and/or vaccine administration. Of note in the latter context is the present finding that concomitant administration of M2e-MAP and a sublethal dose of infectious virus by the i.n. route not only enhanced the M2e(pepnat)-specific serum $\mathrm{Ab}$ titer compared to vaccination with infectious virus or M2e-MAP (plus adjuvants) alone, but affected also the specificity of the response in that essentially all M2e-specific Abs generated in these co-immunized mice displayed M2e(pep-nat)-specificity (Fig 7A and data not shown). The advantage of co-administration of infectious virus and M2e-MAP with regard to strength of protection against heterosubtypic IAV challenge (as used in the present study) merit further investigation, particularly since this protocol may be adaptable to humans in the form of i.n. vaccination with a combination of live attenuated IAV and a M2e-vaccine.

The relation between M2e(pep-nat)-specific Ab titers in sera of parenterally vaccinated mice and strength of protection followed sigmoidal curves (Fig 6A), which suggested that M2e(pep-nat)-specific serum Abs were equally protective in nose, trachea and lung $\left(\mathrm{EC}_{50} \sim 20 \mu \mathrm{g} / \mathrm{ml}\right)$. This was unexpected in view of previous studies showing that systemically administered passive anti-viral Abs of IgG isotypes were significantly less protective in upper than lower airways [24-26]. The reason for this appears to be the lower rate of transudation of serum IgG through the pseudostratified columnar epithelium of upper airways than the thinner epithelium of respiratory airways and alveoli [27]. To confirm that this differential effectiveness applies also to M2e(pep-nat)-specific Abs, we injected fifteen naive BALB/c mice with three different purified mAbs (5 mice/Ab) to achieve a passive serum $\mathrm{Ab}$ concentration of $\sim 20 \mu \mathrm{g} / \mathrm{ml}$ and then challenged the mice by i.n. inoculation of $5 \mu \mathrm{l}$ X31. Determination of virus titers in lung, trachea and nose five days later confirmed the decreasing protective activity of serum $\mathrm{Ab}$ from lower to upper airways, in that mAb-treated mice exhibited, on average, a 100 fold reduction in virus titer in the lung, 30 fold in the trachea and no reduction at all in the nose compared to control mice treated with PBS (data not shown). Accordingly, M2e(pep-nat)-specific serum Ab titers in mice that had been immunized by a parenteral route appeared to account reasonably well for the protection in lung and trachea but not in the nose.

One possible explanation for this difference in protection between actively and passively immunized mice was that active immunization induced substantial levels of M2e(pep-nat)-specific IgA. When dimerized with J chain, IgA is actively transported by the polymeric Ig receptor (pIgR) system through the columnar epithelium of conducting airways and is therefore more abundant than IgG in secretions of upper than lower airways $[27,28]$. Accord- ingly, secretory IgA with virus-neutralizing activity has been shown to be responsible for much of the protection against IAV replication in the nasal cavity of mice, while IgG is more important for protection of respiratory airways [29-31]. However, we could not detect significant levels of M2e(pep-nat)-specific IgA in sera of parenterally vaccinated mice (data not shown), making this explanation untenable. Another possibility, which is discussed in more detail below, is that parenteral vaccination with M2e-MAP induced significant airway-associated immunity. Although induction of strong local airway-associated immunity is generally thought to require administration of antigen into the airways [31-33], there is evidence indicating that parenteral immunization with CT may result in the migration of dendritic cells to mucosa-associated lymphoid tissues and thereby promote some level of mucosa-associated immunity [34,35]. In this study, CT significantly enhanced the systemic $\mathrm{Ab}$ response upon parenteral vaccination but we do not know whether it also resulted in the induction of nasal mucosa-associated immunity that may have restricted virus replication in nasal tissue, independent of serum Ab titer. Finally and probably most likely, immunization with M2e-MAP may have induced not only M2e-specific Abs but also T cells that contributed to protection. This possibility is supported by previous studies showing that vaccination of $\mathrm{BALB} / \mathrm{C}$ mice with M2e-MAP [17] or M2-DNA and M2recombinant adenovirus [9] induced M2e-specific T cell responses, most likely of CD4 phenotype, and that virusspecific CD4 memory $\mathrm{T}$ cells could significantly restrict virus replication in the nose but not the lung [36]. Accordingly, M2e-specific CD4 T cells may have inhibited virus replication in the nose and $\mathrm{M} 2 \mathrm{e}$-specific serum Abs in the lung. This proposition does not conflict with the conclusion of Jegerlehner et al. [6] that M2e-specific T cells played no role in protection of mice against a lethal total respiratory virus challenge, as the lethality of the infection is determined by the level of virus replication in the lung but not the nose. The contrasting finding by Tompkins et al. [9] that $\mathrm{T}$ cells contributed to protection against lethal IAV challenge in mice immunized by M2-DNA and M2recombinant adenovirus may be explained by induction of M2-specific CD8 T cells in these mice. It is well established that virus-specific memory CD8 T cells can contribute to resistance against a lethal IAV challenge.

\section{Route of vaccination and strength of protection}

I.n. vaccination resulted in stronger protection against descending infection than parenteral vaccination (Fig 3C,D). Most remarkably, however, the strength of protection in i.n. vaccinated mice showed no correlation with M2e(pep-nat)-specific serum Ab titers (Table 1). Indeed, several groups of i.n. vaccinated mice with serum $A b$ titers that were completely non-protective in parenterally vacci- 
nated mice showed nevertheless strong protection (Fig $6 \mathrm{~B}, \mathrm{C})$. Several explanations can be considered.

First, i.n. administration of adjuvant alone has been shown to result in a temporary increase in resistance against virus replication in the respiratory tract [37-40]. However, such a non-specific enhancement of resistance is unlikely to have affected the results of this study, since M2e-MAP-vaccinated mice were always compared to control mice that had been vaccinated by the i.n. route with adjuvant alone, thus canceling out adjuvant-induced nonspecific effects.

Second, i.n. vaccination may have induced local, airwayassociated immunity that was not adequately reflected by serum Ab titers. To affect virus replication, Abs must be present in airway secretions. Abs in this location may have two distinct provenances [41]: 1) They may be serum Abs that transudated into extravascular spaces of airway tissues and, in the case of IgG, transudated further into the airway lumen or, in the case of IgA and IgM, became transported through the epithelial cell layer by pIgR. 2) They may have been secreted by B cells located in the lamina propria of airways. As such locally produced Abs, particularly J-chain associated IgA and IgM, can be expected to be delivered more effectively into the airway lumen than into the intravascular compartment, serum Ab titers do not provide a reliable measure of the locally produced fraction of Abs. The importance of nasal administration of vaccine for promotion of local immunity has been documented both in animal models [31,42-45] and humans [46-49]. Once induced, antigen-specific B and T cells may persist in airway tissues for an extended period of time and provide the host with long lasting enhanced protection [50-54]. Accordingly, local M2e(pep-nat)-specific B and possibly also $\mathrm{T}$ cells may have provided strong protection in some i.n. vaccinated mice in the absence of protective serum $\mathrm{Ab}$ titers (Fig 6B,C).

Third, i.n. vaccination may have induced a qualitatively different and more protective immune response than parenteral vaccination. It is well established, for instance, that i.n. vaccination typically promotes a stronger IgA response than parenteral vaccination. The fact that we could not detect significant M2e(pep-nat)-specific IgA in pooled sera of i.n. vaccinated mice (data not shown) does not exclude the possibility that M2e(pep-nat)-specific IgA was produced locally and efficiently transported into airway secretions. In contrast to IgG, locally produced IgA may interact intracellularly with $\mathrm{M} 2 \mathrm{e}$ during its pIgRmediated transport through infected epithelial cells and thereby restrict virus replication [55]. The substantial efficacy of this mechanism in vivo has been demonstrated by passive IgA mAb-mediated clearance of Rotavirus from intestinal epithelium of mice with severe combined immunodeficiency [56]. After its release into airway secretions, secretory M2e(pep-nat)-specific IgA may have lesser protective power than IgG, both in terms of activation of FCR-expressing effector cells and complement. Nevertheless, cell-bound secretory IgA, while incapable of activating effector cells through one of the widely expressed activating FcyRs, may still be able to activate effector cells through interaction with the recently identified Fc $\alpha \mu \mathrm{R}$ in mice [57] or CD86 in humans. In addition, while incapable of activating complement through the classic pathway, IgA may still activate it through the alternative [58] and lectin [59] pathways if complement activation were involved in M2e-Ab-mediated protection. Another potentially important qualitative change observed here after i.n. administration of vaccine was the significant increase in the proportion of M2e(pep-nat)-specific Abs of G2a isotype (Fig 4B). Firstly, IgG2a was the most protective IgG isotype in passive transfer experiments (Fig 5). In addition, if $\mathrm{T}$ cells contributed to protection, the prevalence of IgG2a may indicate a general bias of the response towards type 1 , which is typically associated with optimal T cellmediated protection in viral and bacterial infections. Additional studies are needed to sort out the relative importance of local immunity and quality of the response in the improved protection after i.n. vaccination.

The enhanced protection seen here after i.n. vaccination must be viewed in the context of the challenge used here. It consisted of an infection that was initially confined to the nasal epithelium and allowed to descend from there into the lower respiratory tract over the course of five days. In this scenario, strong immunity in the upper respiratory tract would be expected to have a substantial impact on the progress of the infection. By contrast, the more frequently used challenge with an inoculum of 30-50 $\mu \mathrm{l}$ in anesthetized mice initiates an infection in both upper and lower respiratory tact, and virus titer in lung or survival would hardly if at all be affected by immunity in the upper respiratory tract. We believe this nasal challenge provides a relevant model for the IAV infection in humans.

\section{Conclusion}

M2e-MAP is an effective immunogen as roughly $80 \%$ of the total M2e-MAP-specific $\mathrm{Ab}$ response displayed $\mathrm{M} 2 \mathrm{e}$ (pep) specificity. A variable fraction (on average $15 \%$ ) of these M2e(pep)-specific Abs cross-reacted with presumably native tetrameric M2e expressed by M2-transfected HeLa cells, and the concentration of these M2e(pep-nat)-specific Abs in sera of parenterally immunized mice showed a good correlation with protection against virus challenge. However, M2e(pep-nat)-specific serum Abs did not appear to fully account for protection, particularly in the nose, of M2e-MAP-vaccinated mice, suggesting the contribution of additional protective activities, possibly M2e-specific T cells and/or local airway- 
associated $\mathrm{Ab}$ responses. The latter was supported also by the observation that immunization by the i.n. route resulted in stronger protection than immunization by a parenteral route and that the strength of protection in i.n. vaccinated mice showed no correlation with M2e(pepnat)-specific serum Ab titers. Concomitant i.n. administration of M2e-MAP with infectious virus enhanced the M2e(pep-nat)-specific Ab response and protection compared to i.n. vaccination with M2e-MAP plus adjuvant or infectious virus alone. Concomitant i.n. administration of M2e-MAP and attenuated cold-adapted live virus may be applicable to human vaccination and merits further investigation.

\section{Methods \\ Mice}

Female BALB/c mice (5-6 week old) were purchased from Harlan [60] and maintained in the Institute's Animal Facility in microisolator cages under specific pathogenfree conditions. Mice were rested for $\geq 2$ weeks before use in experiments. All procedures performed on animals were approved by the Institutional Animal Care and Use Committee.

\section{Media, solutions and reagents}

ISC-CM is Iscove's Dulbecco medium (Invitrogen) supplemented with $0.05 \mathrm{mM}$ 2-mercaptoethanol, $0.005 \mathrm{mg} /$ $\mathrm{ml}$ transferrin (Sigma), $2 \mathrm{mM}$ L-glutamine (Mediatech Inc) and $0.05 \mathrm{mg} / \mathrm{ml}$ gentamicin (Mediatech Inc). ISC$\mathrm{CM}$ was further supplemented, as indicated, with fetal bovine serum (FBS, Gemini Bio-products) or bovine serum albumin (BSA, Sigma). PBSN is phosphate buffered saline (pH7.2) supplemented with $3 \mathrm{mM} \mathrm{NaN3}$. Immunostimulatory phosphorothionated oligodeoxynucleotide (ODN) 1826 [61] and cholera toxin (CT) were purchased from Sigma. Multiple antigenic peptides (MAPs) were synthesized in house [62] and have been described previously [17]. The MAPs used here are: G39d (dimer of disulfide-linked MAPs, each containing two M2e(2-25)-peptides and two helper T cell peptides, one (S1) presented by $\mathrm{A}^{\mathrm{d}}$ and the other (S2) by $\mathrm{E}^{\mathrm{d}}$ [63], linked

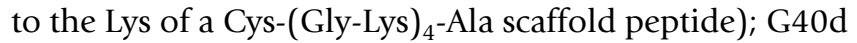
(as G39d but with only one helper T cell peptide linked to

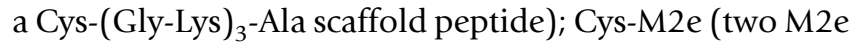
peptides linked to Cys-(Gly-Lys) ${ }_{3}$-Ala) and Cys-bb (Cys(Gly-Lys) ${ }_{3}$-Ala. G39d was used for all but two immunizations. Fig 1 shows the composition and sequence of the MAPs.

\section{Monoclonal Abs}

The M2e-specific hybridoma 14C2 (IgG1) was originally obtained from Zebedee and Lamb [22]. The 14C2 switch variant of G2b isotype was selected by staining 20 million parental (IgG1) hybridoma cells with rat-anti-mouse-G2b $\mathrm{mAb}$ (R1.3-20), sorting by flow cytometry for the $1 \%$ most intensively stained cells, culturing the sorted cells by limiting dilution and testing growing cultures for secretion of IgG1 and IgG2b. A G2a switch variant (14C2-S14) was similarly selected from the G2b switch variant (14C2-S1) by using the rat-anti-mouse-G2a mAb (G2a-36.8) for staining of 14C2-S1 cells. MAbs were purified from protein-free hybridoma medium PFHM-II (Gibco), in which hybridoma cells, initially grown up in ISC-CM $5 \%$ FBS, had been cultured to exhaustion. Purified 14C2S1-4 mAb was used as standard for determination of M2especific Ab concentration by ELISA.

\section{Viruses}

$\mathrm{PR} / 8 / 34$ (H1N1)-Mt.Sinai (PR8) is a highly pathogenic mouse-adapted IAV. 500 TCID $_{50}(50 \%$ tissue culture infectious dose) correspond to $\sim 1 \mathrm{LD}_{50}$ (50\% lethal dose) when administered in $50 \mu \mathrm{l}$ into the respiratory tract of anesthetized mice. PR8-Seq14 is an escape mutant derived from PR8 through fourteen sequential selection steps, each performed in the presence of a distinct PR8-specific $\mathrm{mAb}$ that was capable of neutralizing the penultimate escape mutant. PR8-Seq14 differs from PR8 by 15 amino acid substitutions in HA, is not measurably inhibited in hemagglutination inhibition assay by PR8-specific mouse sera and retains the high pathogenicity of PR8 (observations to be published). X31 is a reassortant between PR8 and A/Aichi/68(H3N2). It contains all PR8-derived genes except those encoding H3 and N2 and is of low pathogenicity.

\section{Immunization, infection and analysis of mice}

For i.n. immunization, $50 \mu \mathrm{l}$ of vaccine preparation (PBS containing $3 \mu \mathrm{g}$ M2e-MAP, $3 \mu \mathrm{g}$ ODN 1826 and $0.5 \mu \mathrm{g}$ CT) was applied to the nares of mice anesthetized by intraperitoneal (i.p.) injection of $0.2 \mathrm{ml}$ ketamine-xylazine $(70 / 7 \mathrm{mg} / \mathrm{kg})$; this results in the aspiration of the vaccine into upper and lower airways. For subcutaneous (s.c.), intramuscular (i.m.) and i.p. immunization, $50 \mu \mathrm{l}$ of vaccine as above was injected into the tail base, quadriceps or peritoneal cavity, respectively, of non-anesthetized mice. Vaccinations were repeated once or twice, typically in four week intervals. Three weeks after primary, secondary or tertiary vaccination, $0.1-0.2 \mathrm{ml}$ blood was collected by puncture of the retro-orbital plexus, and plasma samples were pooled within each immunization group. Four weeks after the last vaccination, anesthetized mice were challenged by administration of $5 \mu \mathrm{l}$ PBS (containing $2000 \mathrm{TCID}_{50}$ of X31) to the nares, dispensing half of the inoculum per nare. This challenge results in a sublethal infection that is initially confined to the nasal epithelium and then descends in naive mice over the next five days into trachea and lung. Five days after infection, mice were euthanized by exsanguination under ketamine/xylazine anesthesia. Nose, trachea with attached extrapulmonary bronchi and lungs were individually dissected and stored 
frozen for subsequent determination of infectious virus titer by MDCK assay as described [36]. Tissue homogenates that scored negative in the MDCK assay (sensitivity threshold: $10^{1.8} \mathrm{TCID}_{50}$ per total nasal and tracheal extract and $10^{2.1} \mathrm{TCID}_{50}$ per lung extract) were tested by inoculation of $50 \mu \mathrm{l}$ undiluted tissue extracts into the allantoic cavity of two embryonated chicken eggs (sensitivity threshold: $10 \mathrm{EID}_{50}$ for nose and trachea and $20 \mathrm{EID}_{50}$ for lung). In some experiments, anesthetized mice were challenged by i.n. administration of PR8 in $50 \mu \mathrm{l}$ PBS; this procedure initiates an infection of upper and lower airways and, depending on virus dose, may be lethal. Infected mice were euthanized three days later for determination of virus titers in airway tissues, or were observed for weight loss.

\section{Determination of M2e-specific Ab concentration by ELISA} For measurement of Abs specific for cell-expressed (presumably native tetrameric) M2e, we used HeLa cells stably transfected with M2-expressing (HeLa-M2) or empty control plasmid (HeLa-C10) as specific and non-specific (background) immunosorbent, respectively [13]. The specific and non-specific immunosorbents used for measurement of M2e-peptide-specific Ab concentration were CysM2e and Cys-bb (see above), respectively [17]. Cys-M2e and Cys-bb were used at equimolar concentration $(85 \mathrm{nM}$ in $0.02 \mathrm{M} \mathrm{NaCl}$ ) to coat wells of polyvinyl plastic plates ( $25 \mu \mathrm{l} /$ well, overnight at room temperature, under cover to prevent evaporation). For measurement of total M2eMAP-specific Ab concentration, we used wells coated as above with M2e-MAP as specific and uncoated wells (only blocked with BSA) as non-specific immunosorbent. Immunosorbent-bound Abs were detected with biotinylated mAb 187 (ATCC HB58, rat-anti-mouse $\kappa$ chain) or G2a-3-6.8 (rat-anti-mouse-G2a) for measurement of Cא- or G2a-expressing Abs, respectively. The difference in OD $(\triangle \mathrm{OD})$ between specific and non-specific immunosorbent was used for quantification of $\mathrm{Ab}$ concentration by comparison to ODs observed with known concentrations of purified M2e-specific mAb 14C2-S1-4 (G2a/Cא) bound to the same immunosorbents. ELISA data were collected with the e-max ELISA reader and analyzed with Softmax Pro software (both Molecular Devices, Sunnyvale, CA).

\section{Statistical analyses}

Prism 4 software [64] was used for plotting and statistical analysis of data as indicated in figure legends.

\section{Competing interests}

The author(s) declare that they have no competing interests.

\section{Authors' contributions}

KM collected blood samples from vaccinated mice, and performed ELISAs and virus titrations. DZ performed the passive protection studies. GK and LO synthesized the M2e-MAPs. WG designed the studies, immunized mice, analyzed data and wrote the manuscript. All authors have read and approved the manuscript.

\section{Acknowledgements}

This study was supported by NIAID grant AI46457 (WG) and the Commonwealth Universal Research Enhancement Program, Pennsylvania Department of Health. The help of Marion Sacks in the preparation of the manuscript and of Soheila Nikpour in the preparation of the figures is gratefully acknowledged.

\section{References}

I. Smith NM, Bresee IS, Shay DK, Uyeki TM, Cox N, Strikas RA, Centers for Disease Control and Prevention (U.S.), Practices USACol: Prevention and control of influenza : recommendations of the Advisory Committee on Immunization Practices (ACIP) Atlanta, GA: U.S. Dept. of Health \& Human Services Centers for Disease Control and Prevention; 2006.

2. Simonsen L, Taylor RJ, Viboud C, Miller MA, Jackson LA: Mortality benefits of influenza vaccination in elderly people: an ongoing controversy. Lancet Infect Dis 2007, 7:658-666.

3. Puck JM, Glezen WP, Frank AL, Six HR: Protection of infants from infection with influenza $A$ virus by transplacentally acquired antibody. J Infect Dis 1980, 142:844-849.

4. Ernst WA, Kim HJ, Tumpey TM, Jansen AD, Tai W, Cramer DV, Adler-Moore JP, Fujii G: Protection against $\mathrm{HI}, \mathrm{H5}, \mathrm{H} 6$ and $\mathrm{H9}$ influenza $A$ infection with liposomal matrix 2 epitope vaccines. Vaccine 2006, 24:5I58-5168.

5. Fan J, Liang X, Horton MS, Perry HC, Citron MP, Heidecker GJ, Fu TM, Joyce J, Przysiecki CT, Keller PM, et al.: Preclinical study of influenza virus A M2 peptide conjugate vaccines in mice, ferrets, and rhesus monkeys. Vaccine 2004, 22:2993-3003.

6. Jegerlehner A, Schmitz N, Storni T, Bachmann MF: Influenza A vaccine based on the extracellular domain of M2: weak protection mediated via antibody-dependent NK cell activity. J Immunol 2004, I 72:5598-5605.

7. Mozdzanowska K, Maiese K, Furchner M, Gerhard W: Treatment of influenza virus-infected SCID mice with nonneutralizing antibodies specific for the transmembrane proteins matrix 2 and neuraminidase reduces the pulmonary virus titer but fails to clear the infection. Virology 1999, 254:138-146.

8. Neirynck S, Deroo T, Saelens X, Vanlandschoot P, Jou WM, Fiers W: $A$ universal influenza $A$ vaccine based on the extracellular domain of the M2 protein. Nat Med 1999, 5:1157-1163.

9. Tompkins SM, Zhao ZS, Lo CY, Misplon JA, Liu T, Ye Z, Hogan RJ, Wu Z, Benton KA, Tumpey TM, Epstein SL: Matrix protein 2 vaccination and protection against influenza viruses, including subtype H5NI. Emerg Infect Dis 2007, 13:426-435.

10. Treanor JJ, Tierney EL, Zebedee SL, Lamb RA, Murphy BR: Passively transferred monoclonal antibody to the $M 2$ protein inhibits influenza A virus replication in mice. J Virol 1990, 64: I 375-I 377.

II. Zharikova D, Mozdzanowska K, Feng J, Zhang M, Gerhard W: Influenza type $A$ virus escape mutants emerge in vivo in the presence of antibodies to the ectodomain of matrix protein 2 . J Virol 2005, 79:6644-6654.

12. Black RA, Rota PA, Gorodkova N, Klenk HD, Kendal AP: Antibody response to the $M 2$ protein of influenza $A$ virus expressed in insect cells. J Gen Virol I993, 74(Pt I): I43-I46.

13. Feng J, Zhang M, Mozdzanowska K, Zharikova D, Hoff H, Wunner W, Couch RB, Gerhard W: Influenza A virus infection engenders a poor antibody response against the ectodomain of matrix protein 2. Virol J 2006, 3:102.

14. Liu W, Li H, Chen YH: N-terminus of M2 protein could induce antibodies with inhibitory activity against influenza virus replication. FEMS Immunol Med Microbiol 2003, 35:14I-I46.

15. Frace AM, Klimov Al, Rowe T, Black RA, Katz JM: Modified M2 proteins produce heterotypic immunity against influenza $A$ virus. Vaccine 1999, 17:2237-2244. 
16. Liu W, Peng Z, Liu Z, Lu Y, Ding J, Chen YH: High epitope density in a single recombinant protein molecule of the extracellular domain of influenza A virus M2 protein significantly enhances protective immunity. Vaccine 2004, 23:366-371.

17. Mozdzanowska K, Feng J, Eid M, Kragol G, Cudic M, Otvos L Jr, Gerhard W: Induction of influenza type $A$ virus-specific resistance by immunization of mice with a synthetic multiple antigenic peptide vaccine that contains ectodomains of matrix protein 2. Vaccine 2003, 21:2616-2626.

18. Slepushkin VA, Katz JM, Black RA, Gamble WC, Rota PA, Cox NJ: Protection of mice against influenza $A$ virus challenge by vaccination with baculovirus-expressed $\mathbf{M} 2$ protein. Vaccine 1995, I 3:1399-1402.

19. Nimmerjahn F, Bruhns P, Horiuchi K, Ravetch JV: FcgammaRIV: a novel FcR with distinct IgG subclass specificity. Immunity 2005 , 23:4|-5I.

20. Nimmerjahn F, Ravetch JV: Divergent immunoglobulin g subclass activity through selective Fc receptor binding. Science 2005, 310:1510-1512.

21. Ben Ahmeida ET, Gregoriadis G, Potter CW, Jennings R: Immunopotentiation of local and systemic humoral immune responses by ISCOMs, liposomes and FCA: role in protection against influenza $A$ in mice. Vaccine 1993, 11:1302-1309.

22. Zebedee SL, Lamb RA: Influenza A virus M2 protein: monoclonal antibody restriction of virus growth and detection of M2 in virions. J Virol 1988, 62:2762-2772.

23. Zhang M, Zharikova D, Mozdzanowska K, Otvos L, Gerhard W: Fine specificity and sequence of antibodies directed against the ectodomain of matrix protein 2 of influenza $A$ virus. Mol Immunol 2006, 43:2195-2206.

24. Gerhard W, Mozdzanowska K, Furchner M, Washko G, Maiese K: Role of the B-cell response in recovery of mice from primary influenza virus infection. Immunol Rev 1997, 159:95-103.

25. Prince GA, Horswood RL, Chanock RM: Quantitative aspects of passive immunity to respiratory syncytial virus infection in infant cotton rats. J Virol 1985, 55:5 17-520.

26. Ramphal R, Cogliano RC, Shands JW Jr, Small PA Jr: Serum antibody prevents lethal murine influenza pneumonitis but not tracheitis. Infect Immun 1979, 25:992-997.

27. Ito R, Ozaki YA, Yoshikawa T, Hasegawa H, Sato Y, Suzuki Y, Inoue R, Morishima T, Kondo N, Sata T, et al.: Roles of anti-hemagglutinin IgA and IgG antibodies in different sites of the respiratory tract of vaccinated mice in preventing lethal influenza pneumonia. Vaccine 2003, 21:2362-2371.

28. Kaltreider $\mathrm{HB}$ : Expression of immune mechanisms in the lung. Am Rev Respir Dis 1976, I 1 3:347-379.

29. Renegar KB, Small PA Jr: Immunoglobulin A mediation of murine nasal anti-influenza virus immunity. | Virol |99|, 65:2146-2148

30. Tamura S, Funato H, Hirabayashi $Y$, Kikuta K, Suzuki Y, Nagamine T, Aizawa C, Nakagawa M, Kurata T: Functional role of respiratory tract haemagglutinin-specific IgA antibodies in protection against influenza. Vaccine 1990, 8:479-485.

3I. Tamura SI, Asanuma H, Ito Y, Hirabayashi Y, Suzuki Y, Nagamine T, Aizawa C, Kurata T, Oya A: Superior cross-protective effect of nasal vaccination to subcutaneous inoculation with influenza hemagglutinin vaccine. Eur J Immunol I992, 22:477-48I.

32. Asanuma $\mathrm{H}$, Aizawa $\mathrm{C}$, Kurata $\mathrm{T}$, Tamura S: IgA antibody-forming cell responses in the nasal-associated lymphoid tissue of mice vaccinated by intranasal, intravenous and/or subcutaneous administration. Vaccine 1998, 16:1257-1262

33. Gallichan WS, Rosenthal KL: Long-lived cytotoxic T lymphocyte memory in mucosal tissues after mucosal but not systemic immunization. J Exp Med 1996, 184: 1879-1890.

34. Enioutina $E Y$, Visic $D$, Daynes RA: The induction of systemic and mucosal immune responses to antigen-adjuvant compositions administered into the skin: alterations in the migratory properties of dendritic cells appears to be important for stimulating mucosal immunity. Vaccine 2000, 18:2753-2767.

35. de Haan L, Verweij WR, Holtrop M, Brands R, van Scharrenburg G], Palache AM, Agsteribbe E, Wilschut J: Nasal or intramuscular immunization of mice with influenza subunit antigen and the B subunit of Escherichia coli heat-labile toxin induces IgA- or IgG-mediated protective mucosal immunity. Vaccine 200I, 19:2898-2907.
36. Liang S, Mozdzanowska K, Palladino G, Gerhard W: Heterosubtypic immunity to influenza type $A$ virus in mice. Effector mechanisms and their longevity. J Immunol 1994, |52:1653-|66|

37. De Filette M, Ramne A, Birkett A, Lycke N, Lowenadler B, Min Jou $W$, Saelens $X$, Fiers $W$ : The universal influenza vaccine M2e$\mathrm{HBC}$ administered intranasally in combination with the adjuvant CTAI-DD provides complete protection. Vaccine 2006, 24:544-55।

38. Matsuo K, Yoshikawa T, Asanuma H, Iwasaki T, Hagiwara Y, Chen Z, Kadowaki SE, Tsujimoto H, Kurata T, Tamura SI: Induction of innate immunity by nasal influenza vaccine administered in combination with an adjuvant (cholera toxin). Vaccine 2000 I 8:27| 3-2722.

39. Rudent A, Zalisz R, Quero AM, Smets P: Enhanced resistance of mice against influenza virus infection after local administration of glycoprotein extracts from Klebsiella pneumoniae. Int I Immunopharmacol 1985, 7:525-531.

40. Spencer JC, Ganguly R, Waldman RH: Nonspecific protection of mice against influenza virus infection by local or systemic immunization with Bacille Calmette-Guerin. J Infect Dis 1977, 136:17|-175

4I. Wagner DK, Clements ML, Reimer CB, Snyder M, Nelson DL, Murphy $B R$ : Analysis of immunoglobulin $G$ antibody responses after administration of live and inactivated influenza $A$ vaccine indicates that nasal wash immunoglobulin $\mathbf{G}$ is a transudate from serum. J Clin Microbiol 1987, 25:559-562.

42. Fazekas de St Groth S, Donnelley M: Studies in experimental immunology of influenza. IV. The protective value of active immunization. Aust J Exp Biol Med Sci 1950, 28:61-75.

43. Fazekas de St Groth S, Donnelley M: Studies in experimental immunology of influenza. III. The antibody response. Aust J Exp Biol Med Sci 1950, 28:45-60.

44. Liew FY, Russell SM, Appleyard G, Brand CM, Beale I: Cross-protection in mice infected with influenza $A$ virus by the respiratory route is correlated with local IgA antibody rather than serum antibody or cytotoxic $\mathbf{T}$ cell reactivity. Eur J Immunol 1984, 14:350-356.

45. Tumpey TM, Renshaw M, Clements JD, Katz JM: Mucosal delivery of inactivated influenza vaccine induces B-cell-dependent heterosubtypic cross-protection against lethal influenza A H5NI virus infection. / Virol 200I, 75:5|4|-5I50.

46. Clements ML, Betts RF, Murphy BR: Advantage of live attenuated cold-adapted influenza $A$ virus over inactivated vaccine for A/Washington/80 (H3N2) wild-type virus infection. Lancet 1984, I:705-708.

47. Clements ML, Betts RF, Tierney EL, Murphy BR: Serum and nasal wash antibodies associated with resistance to experimental challenge with influenza A wild-type virus. J Clin Microbiol 1986, 24:157-160.

48. Johnson PR Jr, Feldman S, Thompson JM, Mahoney JD, Wright PF: Comparison of long-term systemic and secretory antibody responses in children given live, attenuated, or inactivated influenza A vaccine. J Med Virol 1985, 17:325-335.

49. Waldman RH, Mann JJ, Kasel JA: Influenza virus neutralizing antibody in human respiratory secretions. I Immunol 1968, 100:80-85.

50. Brokstad KA, Cox RJ, Eriksson JC, Olofsson J, Jonsson R, Davidsson $A$ : High prevalence of influenza specific antibody secreting cells in nasal mucosa. Scand J Immunol 200I, 54:243-247.

5I. Jones PD, Ada GL: Persistence of influenza virus-specific antibody-secreting cells and B-cell memory after primary murine influenza virus infection. Cell Immunol 1987, 109:53-64.

52. Liang B, Hyland L, Hou S: Nasal-associated lymphoid tissue is a site of long-term virus-specific antibody production following respiratory virus infection of mice. J Virol 200I, 75:54I6-5420.

53. Moyron-Quiroz JE Rangel-Moreno J, Hartson L, Kusser K, Tighe MP, Klonowski KD, Lefrancois L, Cauley LS, Harmsen AG, Lund FE, Randall TD: Persistence and responsiveness of immunologic memory in the absence of secondary lymphoid organs. Immunity 2006, 25:643-654.

54. van Panhuys N, Perret R, Prout M, Ronchese F, Le Gros G: Effector lymphoid tissue and its crucial role in protective immunity. Trends Immunol 2005, 26:242-247. 
55. Mazanec MB, Coudret CL, Fletcher DR: Intracellular neutralization of influenza virus by immunoglobulin $A$ anti-hemagglutinin monoclonal antibodies. J Virol 1995, 69:।339-1343.

56. Burns JW, Siadat-Pajouh M, Krishnaney AA, Greenberg HB: Protective effect of rotavirus VP6-specific IgA monoclonal antibodies that lack neutralizing activity. Science 1996, 272:104-107.

57. Shibuya A, Honda S: Molecular and functional characteristics of the Fcalpha/muR, a novel Fc receptor for IgM and IgA. Springer Semin Immunopathol 2006, 28:377-382.

58. Janoff EN, Fasching C, Orenstein JM, Rubins JB, Opstad NL, Dalmasso AP: Killing of Streptococcus pneumoniae by capsular polysaccharide-specific polymeric IgA, complement, and phagocytes. J Clin Invest 1999, 104: I I39-1 I 47.

59. Roos A, Bouwman LH, van Gijlswijk-Janssen DJ, Faber-Krol MC, Stahl GL, Daha MR: Human IgA activates the complement system via the mannan-binding lectin pathway. J Immunol 200I, 167:286I-2868.

60. Harlan Sprague Dawley, Inc: [http://www.harlan.com].

61. Hartmann G, Weeratna RD, Ballas ZK, Payette P, Blackwell S, Suparto I, Rasmussen WL, Waldschmidt M, Sajuthi D, Purcell RH, et al.: Delineation of a CpG phosphorothioate oligodeoxynucleotide for activating primate immune responses in vitro and in vivo. J Immunol 2000, 164:1617-1624.

62. Kragol G, Otvos L: Orthogonal solid-phase synthesis of tetramannosylated peptide constructs carrying three independent branched epitopes. Tetrahedron 200I, 57:957-966. <Go to ISI $>: / / 000166786700003$

63. Gerhard W, Haberman AM, Scherle PA, Taylor AH, Palladino G, Caton AJ: Identification of eight determinants in the hemagglutinin molecule of influenza virus A/PR/8/34 (HINI) which are recognized by class II-restricted $T$ cells from BALB/c mice. J Virol I99I, 65:364-372.

64. GraphPad Software: [http://www.graphpad.com]

\section{Publish with Bio Med Central and every scientist can read your work free of charge}

"BioMed Central will be the most significant development for disseminating the results of biomedical research in our lifetime. "

Sir Paul Nurse, Cancer Research UK

Your research papers will be:

- available free of charge to the entire biomedical community

- peer reviewed and published immediately upon acceptance

- cited in PubMed and archived on PubMed Central

- yours - you keep the copyright 